\title{
Review of the Role of Fluid Dairy in Delivery of Polyphenolic Compounds in the Diet: Chocolate Milk, Coffee Beverages, Matcha Green Tea, and Beyond
}

\author{
Arpan R. Bhagat \\ 9612 Athens Dr, Argyle, TX 76226 \\ Amélia Martins Delgado \\ University of Algarve, MeditBio - Centre for Mediterranean Bioresources and Food, Campus de Gambelas, 8005-139 Faro, Portugal \\ Manel ISSAOUI \\ University of Kairouan, Faculty of Science and Technology of Sidi Bouzid, Department of Biotechnology, 9100 Sidi Bouzid, \\ Tunisia \\ Nadia Chammem \\ University of Carthage, Institut National des Sciences Appliquées et de Technologie, Laboratoire d'Ecologie et de Technologie \\ Microbienne, 1080 Tunis, Tunisia \\ MARCo Fiorino \\ Studio Tecnico Fiorino, 96100 Syracuse, Italy
}

Alessandra Pellerito and Sofia Natalello

Food Safety Consultants, 90121 Palermo, Italy

Dairy-based functional beverages have been a growing segment as consumer demands for health foods have shifted focus from simply enhancing lifespan to protecting health. Green tea is often limited in use because of poor bioavailability and disagreeable taste. However, milk is considered an ideal platform for the delivery of active polyphenolic compounds in green tea. Furthermore, the antioxidant enzymatic activity and antioxidant index of polyphenols in green tea have been known to be protected through interaction with dairy proteins inside the unstable intestinal environment. In addition, consumption of green tea infused with milk has been found to have a significant impact on reducing skin wrinkles and roughness in elderly subjects, through a decrease in lipid peroxidation and a concomitant reduction in oxidative stress. A similar affinity has been observed between antioxidants in coffee and milk proteins. Dark chocolate has been known to contain significant phenolic content and antioxidant activity. The activation of protein complex NF-kB, which is responsible for cell survival, was found to be significantly reduced upon consumption of cocoa with water, whereas consuming cocoa with milk had no effect on the bioavailability of the phenolic compounds in cocoa. The popularity of dairy as the source for polyphenol fortified beverages in the diet will be dictated by optimization of the technology for maximizing the bioavailability of the antioxidants.

Guest edited as a special report on "Analysis of Major Phenolic Compounds in Foods and Their Health Effects" by Salvatore Parisi. Corresponding author's e-mail: Arpanrbhagat@yahoo.com DOI: https://doi.org/10.5740/jaoacint.19-0129
$\mathrm{I}$ $\mathrm{t}$ is impossible to review your lifestyle without reviewing your diet, which means knowing what each food item can offer to your body. "Food" can be defined in many ways, including legally. In that sense, according to Article 2 of the European Regulation (EC) No. 178/2002, "food" (or "foodstuff") means "any substance or product, whether processed, partially processed or unprocessed, intended to be, or reasonably expected to be ingested by humans" (1). Based on the same reference, food encompasses "drink, chewing gum and any substance, including water, intentionally incorporated into the food during its manufacture, preparation or treatment." Consequently, a food may be of animal, vegetable, or mineral origin. It can be in a solid, liquid, pasty, or powdery state. A fluid food, that is, "a material that flows by itself, under the effect of its own weight and is unable to recover its original shape," can be characterized by its specific rheological proprieties. A fluid food, commonly in the category of drinks or beverages, has the main purpose of satisfying thirst. Drinks can be classed as alcoholic and nonalcoholic. Nonalcoholic beverages, the object of the current review, include a wide range of products, such as water, coffee, tea, chocolate, soft drinks, milk, various combinations of these, etc.

In addition to its main function of providing for the energy and nutritive needs of humans in sufficient quantity and quality, a food must give the consumer a sense of satisfaction and wellbeing through hedonistic attributes. This factor is a triangular relationship between food, health and nutrition, and mood. In other words, food in general, and nonalcoholic beverages in particular, provide for our basic needs and contribute to our health and enjoyment. Tea (the infusion of dried leaves of Camellia sinensis L.), for instance, ranks second in the list of the most widely consumed drinks, in which water takes the first place (2). The addition of milk and/or sucrose is common, aiming at reducing astringency. Coffee is also very popular worldwide. The international coffee market is very active. In the last 50 years, coffee production and consumption have greatly increased all around the world. According to statistics from the 
Food and Agriculture Organization, total exports in 2012 were 7 million tons, corresponding to USD 24 billion, compared to USD 5.1 billion for a total of 5.5 million tons in 2002. The coffee market is sensitive to variations in quantity and quality. Thus, a multitude of coffee varieties, blends, and different forms are presented as final products of distinct quality and price (3). Like tea and cocoa, coffee is often consumed with milk and sugar. One of the most important challenges in the coming years appears to be the characterization of these and other products because of the introduction of new and traditional foods, such as regional recipes, new beverages such as kawa, and the addition of possible molecules or classes of compounds with allergenic power, antibiotic or antimicrobial features, and sweet attitudes (4-7). The need for answers for food authenticity purposes and the defense of traditional products are correlated with the creation and development of analytical methods concerning sugars, fructans, certain oligosaccharides, etc., in various products (8-11). These exigencies also concern polyphenols and associated natural foods.

The most well-known characteristic of polyphenols is their ability to eliminate free radicals. Endogenous antioxidant defense mechanisms are not always sufficient and need to be complemented by dietary components with free radicalscavenging properties. Among those polyphenols, flavonoids in particular are of utmost importance. Korir et al. (12) assessed the antioxidant effect of tea polyphenols in vivo by monitoring the levels of glutathione (GSH) in plasma and various tissues, after demonstrating the clear enhancing effect of tea polyphenols on GSH. GSH is the most abundant intracellular antioxidant. These authors observed the GSH level in plasma to peak about $2 \mathrm{~h}$ after the intake of tea, suggesting a short half-life of antioxidant compounds originating or derived from tea. Korir et al. also observed that the levels of GSH in the brain correlated with the intake of tea, suggesting that some phenolics may cross the brain-blood barrier and scavenge free radicals locally, probably contributing to the avoidance of neurodegenerative diseases and the preservation of mental acuity in the elderly.

Scientific evidence relates dietary intake of phenolic-rich food with lower incidence rates of several chronic diseases. However, many of those health-related statements are formulated without taking into account the changes that phenols may undergo when ingested. The bioavailability of polyphenols is another factor that should be taken into consideration. In a broad sense, bioavailability refers to the "proportion of a nutrient that is digested/absorbed and metabolized through normal pathways" (13). Hence, the bioavailable portion of an active compound refers to the amount of the compound that is available to exert a beneficial action in the body and accounts for the absorption, metabolism, storage, and excretion of the bioactive compound. Considerations about the bioavailability of phenolic compounds are abundant in the literature (14-17). Based on the review of Septembre-Malaterreb et al., bioavailability depends mainly on three factors: intestinal microbiota, molecular structure, and weight, as well as on the interactions with other dietary ingredients, mainly protein in the case of polyphenols (18).

Drinks are not always consumed as is. Thus, coffee can be mixed with milk to produce a "latte" or "cappuccino" beverage; also, chocolate powder may be suspended in milk, without forgetting the famous British tea, which can be flavored with milk, and sugar or honey. So different dietary habits linked to certain regions and cultures may disseminate globally and stimulate innovation elsewhere, resulting in new market opportunities. On the other hand, consumers are more and more concerned about their health and these drinks are important sources of phytonutrients in human diet $(19,20)$. It is then of interest to manufacturers and consumers to be informed about the antioxidant capacity of these drinks, as well as about the bioavailability of their phenolic compounds, which have been associated to health-promoting outcomes.

As exhibited by Gallo et al. (21), phenolic compounds have an affinity to globular proteins and tend to agglomerate (i.e., to form complexes with proteins) with a higher probability as the molecular size of the polyphenol increases. When ingesting a food rich in polyphenols, a consumer's first perception is probably the astringency. This taste results from the interaction of the polyphenols of the food matrix and the protein of the saliva (mainly proline), resulting in the formation of an insoluble complex responsible for the astringency sensation (22). This is an example of a change occurring in the mouth and impacting the sensorial perception of the food by the consumer. But what is the behavior of polyphenols regarding interactions with proteins from the food matrix?

Interactions between polyphenols and proteins can modify the taste of the ingested food as well as the structure of the proteins. The question now is if this interaction has nutritional implications.

\section{Polyphenols and Gut Microbiota}

Ingested polyphenols have different bioavailabilities that are much lower than those of ingested macro- and micronutrients. According to Cardona et al. (23), only $5-10 \%$ of ingested polyphenols are readily absorbed in the small intestine, most probably the ones with lower molecular weight. The rest follow their way to the colon, where they are partially metabolized by gut microbiota. The low-molecular-weight derivatives of polyphenols either are absorbed into the bloodstream or act locally, affecting the balance of microbial populations and/or their enzymatic activities.

In turn, the absorbed phenolic compounds (either those actually ingested or the breakdown products of gut microbes) undergo chemical changes in enterocytes and/or hepatocytes through deglycosylation and hydrolysis. The resultant watersoluble metabolites (e.g., lactones and phenolic acids) may then enter the bloodstream, reaching various organs or eliminated in feces or in urine $(23,24)$.

Ibero-Baraibar et al. (25) performed a controlled interventional clinical trial to evaluate to what extent flavanol-rich foods can prevent cardiometabolic alterations in obese subjects. Cocoa extract was used, given its high content of polyphenols that are often associated with benefits for blood pressure, normal blood biochemical markers (namely cholesterol levels), insulin resistance, and inflammation. These authors observed that flavanol monomers (epicatechin and catechin) were readily absorbed into the bloodstream, whereas procyanidins were poorly absorbed, with the exception of procyanidin dimer

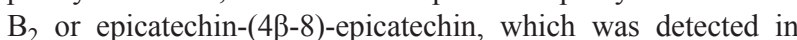
the plasma. To study the bioavailability of such compounds, Ibero-Baraibar et al. (25) measured the concentration of the ingested compounds and 14 of their derivatives in 
plasma. According to their findings, the monomers that are absorbed undergo changes in the liver or in the small intestine involving methylation, glycosylation, and sulfonation before being released into plasma. Once in the bloodstream, these metabolites undergo further changes in the liver and return back to the small intestine via enterohepatic circulation. According to the same authors, the polymeric forms reach the colon, where they are degraded by gut bacteria. The resulting phenolic acids are then absorbed into the circulation, undergoing the cycle previously described. The half-life of flavanols in plasma is about $6-8 \mathrm{~h}$, reaching a maximum value 1-2 hours after intake. Although a dose-response relationship was not established, the authors attributed the effects on cardiometabolic markers to the bioavailable phenolics and observed that, in addition to the nonabsorbed fraction, which is eliminated in feces, the phenolic compounds are eliminated from the bloodstream by the kidneys, which transfer them to the urine (25).

The intake of different polyphenols may modify the gut microbial composition of human subjects, namely the Bacteroides-to-Firmicutes ratio $(23,24)$. Cardona et al. (23) refer to animal model studies that showed a significant increase of the Bacteroides group as a consequence of a tannin-rich diet. Cardona et al. (23) and Liu et al. (24) observe that green tea can increase the population of Bifidobacteria and Lactobacillus while repressing pathogenic bacteria, such as some Clostridium spp.

Conversely, the potential health-promoting effects of dietary polyphenols depend on the individual gut microbiome. The relationship between polyphenols and gut microbiota is bidirectional. On one hand, certain polyphenols favor certain bacterial species over others, as well as modulating their enzymatic activities. On the other hand, individual composition of gut microbiota is thought to interfere with the extent of the beneficial effects of polyphenols, depending on their capacity to break them down (23).

Thus, both food polyphenols and their microbial metabolites should be taken into account when assessing bioavailability and health outcomes.

\section{Tea}

Green and black teas are the two most-consumed types when speaking of tea products. They differ in polyphenol composition because of the different processing steps. On the one hand, green tea is rich in catechins, namely in epigallocatechin-3gallate (EGCG), recognized for its free radical-scavenging and anticancer properties $(12,23)$. On the other hand, as the obtainment of black tea involves the oxidization process, the final product is rich in catechin oxidation products such as theaflavins and thearubigins, which have been implicated in the protection against cardiovascular diseases through several mechanisms (12).

Besides these major differences, a wide variation in individual compounds is observed within each type of tea (Tables 1 and 2) due to differences in the cultivar, agronomic and climate factors, etc. The same applies to coffee and cocoa, and any consideration about individual components and mechanisms should be regarded as guidance only.

Antimicrobial properties have been attributed to tea phenolic compounds, namely to catechins and theaflavins. In this respect, Cardona et al. (23) refer to in vitro studies in which the addition of tea polyphenols to the culture media inhibited the growth of pathogenic bacteria (such as Clostridium difficile), whereas the growth of commensals (such as Bifidobacteria and Lactobacillus spp.) was unaffected or stimulated. The ability of lactic acid bacteria is well-known and is used in some vegetable fermentation (e.g., deglycosilation allows the bacteria to use the sugar moiety as carbon source, while the bitter taste is reduced).

In the case of the bacterial species that do not have such enzymatic systems, polyphenols most probably disrupt the cell membrane, and Gram-negative bacteria are more resistant than Gram-positives because of wall composition. Sensitization of methicillin-resistant Staphylococcus aureus to $\beta$-lactam antibiotics was reported to be caused by epicatechin gallate from green tea by a mechanism that involves structural changes to wall teichoic acids (23). The same authors also report another study that shows that green tea polyphenols inactivate VacA toxin, a major virulence factor from Helicobacter pylori, and also suppress its urease activity. Some polyphenols from food may influence some bacterial enzymatic activity and thus indirectly impact cancer risk (23). Other studies reported by the same authors note that tea catechins such as EGCG mediate various cellular events with anticancer protective effects. It is not certain if the necessary bioavailable concentrations of these compounds can be obtained from a regular equilibrated diet.

Such health outcomes are conditioned by gut microbiota because of their active role in the transformation of phenolics.

As mentioned above, green tea is rich in catechins, of which, according to Liu et al. (24), only $8-17 \%$ are bioavailable in the small intestine because of their low transepithelial permeability. The nonabsorbed molecules are stepwise transformed into simple phenolic acids and other simple metabolites. Liu et al. categorize the involved reactions into three types: galloyl ester hydrolysis, C-ring opening, and further sequential modification of the reaction products (24). According to the same authors, by the end of the metabolic pathway, benzene rings of phenolic acids can be opened, allowing its conversion into short-chain fatty acids such as acetate and butyrate.

In the case of black tea, theaflavins and thearubigins predominate as part of a complex fraction of oxidization products of catechins. The knowledge of the metabolic pathways involved in the degradation of black tea phenolics is limited. It is thought that the degradation pathways of these more complex molecules involve a series of steps, some of which are similar to those described for catechin degradation. According to Liu et al. (24), ring cleavage and aliphatic-chain shortening can be postulated, as, finally, a series of low-molecular-weight compounds are obtained, including phenylpropionic, phenylacetic, and benzoic acids and short-chain fatty acids.

Thus, as above, beneficial health outcomes of tea (green and black) are attributable to the original polyphenols from the tea and phase I and phase II metabolites from enterocytes and hepatocytes, as well as a wide range of compounds produced by gut microbiota.

\section{Cocoa}

Cocoa is very rich in phenolics, mainly flavanols (catechin monomers, dimers, and oligomers), procyanidins, and tannins (Table 3). Ibero-Baraibar et al. (25) report the 
1368 Bhagat ET AL.: Journal of AOAC International Vol. 102, No. 5, 2019

Table 1. Polyphenols of tea: discrimination of compounds and average content of each one for infusions of black tea ${ }^{a}$

\begin{tabular}{|c|c|c|c|}
\hline Chemical name & $\begin{array}{l}\text { Avg. concn, } \\
\mathrm{mg} / 100 \mathrm{~mL}\end{array}$ & Chemical name & $\begin{array}{l}\text { Avg. concn, } \\
\mathrm{mg} / 100 \mathrm{~mL}\end{array}$ \\
\hline \multicolumn{4}{|c|}{ Tea (black), infusion } \\
\hline \multicolumn{2}{|c|}{ Flavonoids } & \multicolumn{2}{|l|}{ Flavanols } \\
\hline & & Kaempferol 3-O-galactoside & 0.35 \\
\hline$(+)$-Catechin & 2.45 & & \\
\hline$(+)$-Gallocatechin & 14.01 & & \\
\hline (+)-Gallocatechin 3-O-gallate & 0.67 & Kaempferol 3-O-glucosyl-rhamnosyl-galactoside & 0.28 \\
\hline (-)-Epicatechin & 3.94 & & \\
\hline (-)-Epicatechin 3-O-gallate & 7.34 & Kaempferol 3-O-glucosyl-rhamnosyl-glucoside & 0.67 \\
\hline (-)-Epigallocatechin & 7.19 & & \\
\hline Procyanidin dimer (B1-B4, B7) & 4.14 & Quercetin 3-O-arabinoside & 0.02 \\
\hline Procyanidin trimer $\mathrm{C} 1$ & 0.76 & Quercetin 3-O-galactoside & 0.73 \\
\hline Prodelphinidin dimer B3 & 1.65 & Quercetin 3-O-glucoside & 1.31 \\
\hline Theaflavin & 3.27 & Quercetin 3-O-glucosyl-rhamnosyl-galactoside & 0.67 \\
\hline Theaflavin 3'-O-gallate & 4.08 & Quercetin 3-O-glucosyl-rhamnosyl-glucoside & 1.10 \\
\hline Theaflavin 3,3'-O-digallate & 3.52 & Quercetin 3-O-rhamnoside & 0.06 \\
\hline Theaflavin 3-O-gallate & 1.58 & Quercetin 3-O-rhamnosyl-galactoside & 0.27 \\
\hline \multicolumn{4}{|l|}{ Phenolic acids } \\
\hline Hydroxybenzoic acids & & Quercetin 3-O-rutinoside & 1.62 \\
\hline 5-O-Galloylquinic acid & 11.57 & & \\
\hline Gallic acid & 4.63 & & \\
\hline 3-p-Coumaroylquinic acid & 0.13 & & \\
\hline 4-Caffeoylquinic acid & 1.20 & & \\
\hline 4-p-Coumaroylquinic acid & 0.84 & & \\
\hline 5-Caffeoylquinic acid & 0.20 & & \\
\hline \multicolumn{4}{|l|}{ Procyanidin dimer B1-B4, B7 } \\
\hline Phenolic acids & & Quercetin 3-O-rutinoside & 1.46 \\
\hline \multicolumn{4}{|l|}{ Hydroxybenzoic acids } \\
\hline 5-O-Galloylquinic acid & 9.41 & & \\
\hline Gallic acid & 0.49 & & \\
\hline \multicolumn{4}{|l|}{ Hydroxycinnamic acids } \\
\hline 3-Caffeoylquinic acid & 0.33 & & \\
\hline 5-Caffeoylquinic acid & 2.30 & & \\
\hline
\end{tabular}

a Table 1 presents data from Phenol-Explorer version $3.6(19,26)$.

average content of flavanols in cocoa extract to be about $30 \%$ (w/w). According to Cardona et al. (23), catechins and other phenolics from cocoa have been suggested to have a protective effect against caries, based on in vitro and in vivo studies, probably involving the inhibition of the synthesis of water-insoluble glucans or the sequestration of metal ions, depriving the bacteria of microelements. On the other hand, changes in flavanols from dark chocolate (mainly flavan3-ols) induced by gut microbiota were reported to have antiinflammatory activity and to impact mood in a controlled human trial. However, the positive effects on mood and on potentially lasting psychological health were much more evident in the emotionally stable subjects (control) than in those suffering from anxiety and related disorders (23).

In a human interventional study, Ibero-Baraibar et al. (25) noted significant correlations between the intake of cocoa extract and blood pressure control, as well as in improving the oxidized low-density lipoprotein cholesterol levels, especially in obese subjects.

\section{Coffee}

Coffee is a major dietary source of polyphenols globally, mainly represented by hydroxycinnamates such as caffeic acid 
Table 2. Polyphenols of tea: discrimination of compounds and average content of each one for infusions of green tea ${ }^{a}$

\begin{tabular}{|c|c|c|c|}
\hline Chemical name & $\begin{array}{l}\text { Avg. concn, } \\
\mathrm{mg} / 100 \mathrm{~mL}\end{array}$ & Chemical name & $\begin{array}{l}\text { Avg. conch } \\
\mathrm{mg} / 100 \mathrm{~mL}\end{array}$ \\
\hline \multicolumn{4}{|c|}{ Tea (green), infusion } \\
\hline \multicolumn{2}{|c|}{ Flavonoids } & \multicolumn{2}{|l|}{ Flavanols } \\
\hline & & Kaempferol 3-O-galactoside & 0.24 \\
\hline$(+)$-Catechin & 0.70 & & \\
\hline$(+)$-Gallocatechin & 2.26 & Kaempferol 3-O-glucoside & 1.29 \\
\hline (+)-Gallocatechin 3-O-gallate & 0.47 & & \\
\hline (-)-Epicatechin & 7.93 & Kaempferol 3-O-rutinoside & 0.95 \\
\hline (-)-Epicatechin 3-O-gallate & 7.50 & & \\
\hline (-)-Epigallocatechin & 19.68 & Quercetin 3-O-galactoside & 0.97 \\
\hline (-)-Epigallocatechin 3-O-gallate & 27.16 & & \\
\hline \multicolumn{4}{|l|}{ Procyanidin dimer B1-B4, B7 } \\
\hline Phenolic acids & & Quercetin 3-O-rutinoside & 1.46 \\
\hline \multicolumn{4}{|l|}{ Hydroxybenzoic acids } \\
\hline 5-O-Galloylquinic acid & 9.41 & & \\
\hline Gallic acid & 0.49 & & \\
\hline \multicolumn{4}{|l|}{ Hydroxycinnamic acids } \\
\hline 3-Caffeoylquinic acid & 0.33 & & \\
\hline 5-Caffeoylquinic acid & 2.30 & & \\
\hline
\end{tabular}

a Table 2 presents data from Phenol-Explorer version $3.6(19,26)$.

Table 3. Polyphenols of cocoa: discrimination of compounds and average content of each one for cocoa powder and beverages (instant cocoa or chocolate beverage, with sugar, ready-to-drink, and reconstituted with standard semi-skimmed milk) ${ }^{a}$

\begin{tabular}{|c|c|c|c|}
\hline Chemical name & $\begin{array}{l}\text { Avg. concn, } \\
\mathrm{mg} / 100 \mathrm{~mL}\end{array}$ & Chemical name & Avg. concn, mg/100 mL \\
\hline \multicolumn{4}{|c|}{ Cocoa, powder } \\
\hline Flavonoids & & \multicolumn{2}{|c|}{ Other polyphenols } \\
\hline Flavanols & & \multicolumn{2}{|c|}{ Alkylphenols } \\
\hline$(+)$-Catechin & 107.75 & 3-Methylcatechol & $1.00 \times 10^{-2} \mathrm{mg} / 100 \mathrm{~g}$ (fresh weight) \\
\hline (-)-Epicatechin & 158.30 & 4-Ethylcatechol & $1.80 \times 10^{-3} \mathrm{mg} / 100 \mathrm{~g}$ (fresh weight) \\
\hline \multirow{2}{*}{$\begin{array}{l}\text { (-)-Epicatechin-(2a-7)(4a-8)-epicatechin } \\
\text { 3-O-galactoside }\end{array}$} & 5.00 & 4-Methylcatechol & $9.80 \times 10^{-3} \mathrm{mg} / 100 \mathrm{~g}$ (fresh weight) \\
\hline & & \multicolumn{2}{|c|}{ Hydroxybenzaldehydes } \\
\hline Cinnamtannin A2 & 33.17 & Vanillin & 0.10 \\
\hline Procyanidin dimer B1 & 112.00 & \multicolumn{2}{|c|}{ Hydroxycoumarins } \\
\hline Procyanidin dimer B2 & 71.57 & Mellein & 0.03 \\
\hline Procyanidin trimer $\mathrm{C} 1$ & 23.83 & Others & \\
\hline Phenolic acids & & Catechol & 0.12 \\
\hline Hydroxybenzoic acids & & Phenol & $3.67 \times 10^{-3} \mathrm{mg} / 100 \mathrm{~g}$ (fresh weight) \\
\hline Benzoic acid & 0.06 & Pyrogallol & 0.18 \\
\hline \multicolumn{4}{|l|}{ Hydroxycinnamic acids } \\
\hline Caffeoyl aspartic acid & 37 & & \\
\hline \multicolumn{4}{|c|}{ Chocolate, milk, beverage } \\
\hline Flavonoids & & \multicolumn{2}{|c|}{ Phenolic acids } \\
\hline Flavanols & & \multicolumn{2}{|c|}{ Hydroxycinnamic acids } \\
\hline$(+)$-Catechin & 8.65 & Caffeoyl aspartic acic & 0.90 \\
\hline
\end{tabular}

a Table 3 presents data from Phenol-Explorer version $3.6(19,26)$. 
and chlorogenic acid. The former is a hydroxycinnamic acid and, when conjugated with quinic acid, forms 5-O-caffeyolquinnic acid, or chlorogenic acid. It is the most abundant compound in coffee, followed by 4-caffeoylquinic acid, 3-caffeoylquinic acid, and 4-feruloylquinic acid (Tables 4 and 5).

Caffeic acid, like other simple phenols, is readily absorbed and detected in plasma, unchanged or after modification in enterocytes and/or hepatocytes. Chlorogenic acid is absorbed to a lesser extent, and Gonthier et al. (27) hypothesized that gut microbiota may play a crucial role in the bioavailability of this and other poorly absorbed polyphenols, perhaps also impacting health outcomes. To clarify the bioavailability and the role of gut microbiota in polyphenol's metabolism and bioavailability, Gonthier et al. monitored the chemical transformations of such compounds by following up an in vitro fermentation with a gut microbiota population. These authors observed that the culture broth was depleted of caffeic acid and its esters (e.g., chlorogenic acid) in about $2 \mathrm{~h}$ of incubation with the active fecal microbiota. In this in vitro model, the following intermediates were identified: 3-hydroxyphenilpropionic acid, the major degradation compound of caffeic acid, and chlorogenic acid, and benzoic acids. All of them disappeared after $4 \mathrm{~h}$, suggesting further conversion into a variety of other phenolics, such as quinic acid, hydroxybenzoic acids, coumaric acids, ferulic acid, and vanillic acid, which were among the list of identified compounds. This study confirmed the ability of gut microbiota to carry out dehydroxylations and other modifications to polyphenols, thus most probably influencing the bioavailability of these phytonutrients. Together with their interactions with colonic mucosa, gut microbiota are likely to be important in diet-related health outcomes (27).

Derivatives of chlorogenic and caffeic acid, formed by intestinal cells or by gut bacteria, are noted by other authors as modulating the activity of enzymes involved in detoxication and inflammation in human adenoma cells (23). The same authors cite studies that support the anticancer activity of coffee phenolics. Hence, caffeic acid inhibited colon cancer metastasis and neoplastic cell transformation in animal models.

\section{Interactions of Polyphenols with Food Matrix Components}

The astringent character of polyphenols, namely catechins, is well known, as is the capacity of these classes of compounds

Table 4. Polyphenols of coffee: discrimination of compounds and average content of each one for different types of coffee preparations (with the exclusion of pure Arabica and Robusta types) ${ }^{a}$

\begin{tabular}{|c|c|c|c|}
\hline Chemical name & $\begin{array}{l}\text { Avg. concn, } \\
\text { mg/100 mL }\end{array}$ & Chemical name & $\begin{array}{l}\text { Avg. concn, } \\
\mathrm{mg} / 100 \mathrm{~mL}\end{array}$ \\
\hline \multicolumn{2}{|c|}{ Coffee beverage (filter), decaffeinated } & \multicolumn{2}{|c|}{ Coffee beverage (filter) } \\
\hline \multicolumn{2}{|c|}{ Phenolic acids } & \multicolumn{2}{|c|}{ Phenolic acids } \\
\hline \multicolumn{2}{|c|}{ Hydroxycinnamic acids } & \multicolumn{2}{|c|}{ Hydroxycinnamic acids } \\
\hline 3,4-Dicaffeoylquinic acid & 7.55 & 3,4-Dicaffeoylquinic acid & 2.66 \\
\hline 3,5-Dicaffeoylquinic acid & 6.34 & 3,5-Dicaffeoylquinic acid & 1.55 \\
\hline 3-Caffeoylquinic acid & 57.9 & 3-Caffeoylquinic acid & 51.80 \\
\hline 3-Feruloylquinic acid & 2.74 & 3-Feruloylquinic acid & 4.17 \\
\hline 4,5-Dicaffeoylquinic acid & 8.34 & 4,5-Dicaffeoylquinic acid & 2.05 \\
\hline 4-Caffeoylquinic acid & 60.29 & 4-Caffeoylquinic acid & 59.60 \\
\hline 4-Feruloylquinic acid & 9.51 & 4-Feruloylquinic acid & 8.75 \\
\hline \multirow[t]{2}{*}{ 5-Feruloylquinic acid } & 8.98 & 5-Feruloylquinic acid & 11.69 \\
\hline & & Caffeic acid & 0.03 \\
\hline \multicolumn{2}{|c|}{ Other polyphenols } & \multicolumn{2}{|c|}{ Other polyphenols } \\
\hline \multicolumn{2}{|c|}{ Alkylmethoxyphenols } & \multicolumn{2}{|c|}{ Alkylmethoxyphenols } \\
\hline 4-Ethylguaiacol & 1.18 & 4-Ethylguaiacol & 0.64 \\
\hline 4-Vinylguaiacol & 0.75 & 4-Vinylguaiacol & 0.46 \\
\hline Methoxyphenols & & \multicolumn{2}{|c|}{ Alkyl phenols } \\
\hline Guaiacol & 0.27 & 3-Methylcatechol & 0.10 \\
\hline Others & & 4-Ethylcatechol & 0.13 \\
\hline Catechol & 0.04 & 4-Methylcatechol & 0.04 \\
\hline \multirow[t]{5}{*}{ Phenol } & 0.07 & \multicolumn{2}{|c|}{ Methoxyphenols } \\
\hline & & \multicolumn{2}{|c|}{ Others } \\
\hline & & Catechol & 0.41 \\
\hline & & Phenol & 0.12 \\
\hline & & Pyrogallol & 0.54 \\
\hline
\end{tabular}

\footnotetext{
a Table 4 presents data from Phenol-Explorer version $3.6(19,26)$.
} 
Table 5. Polyphenols of coffee: discrimination of compounds and average content of each one for Arabica and Robusta coffee preparations $^{a}$

\begin{tabular}{|c|c|c|c|}
\hline Chemical name & $\begin{array}{l}\text { Avg. concn, } \\
\mathrm{mg} / 100 \mathrm{~mL}\end{array}$ & Chemical name & $\begin{array}{l}\text { Avg. concn, } \\
\mathrm{mg} / 100 \mathrm{~mL}\end{array}$ \\
\hline \multicolumn{2}{|c|}{ Arabica coffee beverage (filter) } & \multicolumn{2}{|c|}{ Robusta coffee beverage (filter) } \\
\hline \multicolumn{2}{|c|}{ Phenolic acids } & \multicolumn{2}{|c|}{ Phenolic acids } \\
\hline \multicolumn{2}{|c|}{ Hydroxycinnamic acids } & \multicolumn{2}{|c|}{ Hydroxycinnamic acids } \\
\hline 3,4-Dicaffeoylquinic acid & 3.53 & 3,4-Dicaffeoylquinic acid & 5.96 \\
\hline 3,5-Dicaffeoylquinic acid & 2.65 & 3,5-Dicaffeoylquinic acid & 4.42 \\
\hline 4,5-Dicaffeoylquinic acid & 1.54 & 3-Caffeoylquinic acid & 32.26 \\
\hline 4-Caffeoylquinic acid & 19.00 & 4,5-Dicaffeoylquinic acid & 3.09 \\
\hline 4-Feruloylquinic acid & 13.26 & 4-Caffeoylquinic acid & 36.46 \\
\hline 5-Caffeoylquinic acid & 43.09 & 4-Feruloylquinic acid & 30.05 \\
\hline 5-Feruloylquinic acid & 4.64 & 5-Caffeoylquinic acid & 75.80 \\
\hline \multicolumn{2}{|l|}{ Other polyphenols } & 5-Feruloylquinic acid & 16.57 \\
\hline \multicolumn{2}{|c|}{ Alkylphenols } & & \\
\hline 3-Methylcatechol & 0.11 & & \\
\hline 4-Ethylcatechol & 0.13 & & \\
\hline 4-Methylcatechol & 0.04 & & \\
\hline \multicolumn{4}{|l|}{ Others } \\
\hline Catechol & 0.54 & & \\
\hline Pyrogallol & 0.39 & & \\
\hline
\end{tabular}

a Table 5 presents data from Phenol-Explorer version $3.6(19,26)$.

to denature proteins. Also, glycosylation reactions involving polyphenols are described above.

Thus, the habit of many consumers of adding milk and/ or sugar to tea and coffee comes with consequences, besides masking the astringency sensation conveyed by tannins. Added to these blends, industrial manufacturing processes for coffee, cocoa, and tea-based beverages and foodstuffs most often include steps to eliminate polyphenols, aiming at reducing bitterness and astringency to please such consumers.

Zhang et al. (28) studied the behavior of phenolic acids (chlorogenic acid, caffeic acid, ferulic acid, and coumaric acid) in the presence of milk proteins. The study aimed to better understand, from a chemical point of view (e.g., binding patterns, binding constants, and effects of complexation on the conformation of whey proteins), interactions between $\alpha$-lactalbumin and $\beta$-lactoglobulin and some phenolic acids belonging to the most-consumed beverages when mixed with milk. The authors used fluorescence spectroscopy, circular dichroism, and FTIR spectroscopy. Obtained results showed that the configuration of the whey protein was modified, which triggered a significant decrease in the $\alpha$-helix amount and, at the same time, an increase in the amounts of leaves and rotating structures. The authors have qualified this kind of behavior by static quenching. The complex is, in fact, a result of the interaction of phenolic acids with the whey protein structural subunits $(\mathrm{C}=\mathrm{O}$ and $\mathrm{C}-\mathrm{N})$. Hence, phenolic acids induced an alteration in the helical structure content of the whey protein, which may be a sign of decreased stability (28).

Korir et al. (12) studied the effect of the addition of milk and sweeteners to tea, both in vitro by measuring total antioxidant activity and in vivo by monitoring the levels of GSH. These authors observed that the addition of more than $2 \%$ of milk to black tea affected its antioxidant activity in a concentrationdependent manner. Proteins rich in proline, such as caseins, generally have a strong affinity for the hydroxyl groups of flavonoids. Moreover, their flexible secondary structure facilitates the establishment of hydrogen bonds, further blocking any remaining polyphenol reactive sites.

The same authors observed the same effect after the addition of sucrose and honey to black tea, either plain or with milk. As expected, the decrease in the antioxidant activity was more marked in tea with milk. Korir et al. (12) explain that complex compounds such as pentagalloylglucose, tretragalloylglucose, and trigalloylglucose are likely to be formed upon the reaction of glucose with the gallate moiety. Milk proteins may then interact with these glycosylated molecules through hydrophobic interactions and hydrogen bridging, thus altering their biological activity.

Surprisingly, stevia glycosides (300 times sweeter than sugar) did not significantly affected the antioxidant activity of tea, with or without milk, in the concentration range normally used by consumers. The results were found to be statistically significant, even taking into account that stevia has some antioxidant activity (12).

In short, polyphenols easily react with components from the food matrixes, thus affecting the nutritional properties of the food. Because they precipitate proteins and sequestrate metal ions, they have been known as antinutrients. Nowadays, these compounds are regarded as important phytonutrients, the beneficial properties of which are also negatively affected by certain processes. Adding milk or sugar to coffee or tea (aiming at reducing bitterness and astringency) comes with consequences for the nutritional value of the food by affecting the bioavailability of milk proteins (caseins) as well 
as the polyphenols' free radical-scavenging properties and dramatically decreasing or impairing the health-beneficial properties of such beverages. However, sweetening tea (and possibly also coffee) with stevia does not affect its antioxidant capacity, which is good news for those who appreciate sweet beverages.

\section{References}

(1) Regulation (EC) No. 178/2002 (2002) Off. J. Eur. Communities: Legis. L31, 1-24, https://eur-lex.europa.eu/legal-content/EN/ TXT/PDF/?uri=OJ:L:2002:031:FULL\&from=EN

(2) Khan, N., \& Mukhtar, H. (2007) Life Sci. 81, 519-533. doi:10.1016/j.lfs.2007.06.011

(3) FAO Statistical Pocketbook: Coffee 2015, Food and Agriculture Organization of the United Nations, Rome, Italy, http://www. fao.org/3/a-i4985e.pdf

(4) Austin, S., van Gool, M., Parisi, S., Bhandari, S., Haselberger, P., Jaudzems, G., \& Sullivan, D. (2018) J. AOAC Int. 101, 1270-1271. doi:10.5740/jaoacint. SMPR2014.003

(5) Dentali, S.J., Amarillas, C., Blythe, T., Brown, P.N., Bzhelyansky, A., Fields, C., Johnson, H.E., Krepich, S., Kuszak, A., Metcalfe, C., Monagas, M., Mudge, E., Parisi, S., Reif, K., Rimmer, C.A., Sasser, M., Solyom, A.M., Stewart, J., Szpylka, J., Tims, M.C., Van Breemen, R., You, H., Zhao, H., Zielinski, G., \& Coates, S.G. (2018) J. AOAC Int. 101, 1256-1260. doi:10.5740/jaoacint.SMPR2018.005

(6) Popping, B., Allred, L., Bourdichon, F., Brunner, K., Diaz-Amigo, C., Galan-Malo, P., Lacorn, M., North, J., Parisi, S., Rogers, A., Sealy-Voyksner, J., Thompson, T., \& Yeung, J. (2018) J. AOAC Int. 101, 185-189. doi:10.5740/jaoacint.17-0425

(7) Sharma, R.K., \& Parisi, S. (2016) Toxins and Contaminants in Indian Food Products, Springer International Publishing, Cham, Switzerland. doi:10.1007/978-3-319-48049-7

(8) Parisi, S. (2018) J. AOAC Int. 101, 914-915. doi:10.5740/ jaoacint. 17-0444

(9) Mania, I., Barone, C., Pellerito, A., Laganà, P., \& Parisi, S. (2017) Ind. Aliment. 56, 18-22

(10) Delgado, A.M., Vaz Almeida, M.D., \& Parisi, S. (2016) Chemistry of the Mediterranean Diet, Springer International Publishing, Cham, Switzerland. doi:10.1007/978-3-319-29370-7

(11) Zaccheo, A., Palmaccio, E., Venable, M., Locarnini-Sciaroni, I., \& Parisi, S. (2016) Food Hygiene and Applied Food Microbiology in an Anthropological Cross Cultural Perspective, Springer International Publishing, Cham, Switzerland. doi:10.1007/978-3-319-44975-3
(12) Korir, M.W., Wachira, F.N., Wanyoko, J.K., Ngure, R.M., \& Khalid, R. (2014) Food Chem. 145, 145-153. doi:10.1016/j. foodchem.2013.08.016

(13) Forbes, R.M., \& Erdman, J.W., Jr (1983) Annu. Rev. Nutr. 3, 213-221. doi:10.1146/annurev.nu.03.070183.001241

(14) Renouf, M., Marmet, C., Guy, P., Fraering, A.L., Longet, K., Moulin, J., Enslen, M., Barron, D., Cavin, C., Dionisi, F., Rezzi, S., Kochhar, S., Steiling, H., \& Williamson, G. (2010) J. Nutr. 140, 259-263. doi:10.3945/jn.109.113027

(15) Serafini, M., Bugianesi, R., Maiani, G., Valtuena, S., De, S.S., \& Crozier, A. (2003) Nature 424, 1013. doi:10.1038/4241013a

(16) Keogh, J.B., McInerney, J., \& Clifton, P.M. (2007) J. Food Sci. 72, S230-S233. doi:10.1111/j.1750-3841.2007.00314.x

(17) Roura, E., Andres-Lacueva, C., Estruch, R., Mata-Bilbao, M.L., Izquierdo-Pulido, M., Waterhouse, A.L., \& Lamuela-Raventos, R.M. (2007) Ann. Nutr. Metab. 51, 493-498. doi:10.1159/000111473

(18) Septembre-Malaterreb, A., Remizeb, F., \& Pouchereta, P. (2018) Food Res. Int. 104, 86-99. doi:10.1016/j.foodres.2017.09.031

(19) Neveu, V., Perez-Jiménez, J., Vos, F., Crespy, V., du Chaffaut, L., Mennen, L., Knox, C., Eisner, R., Cruz, J., Wishart, D., \& Scalbert, A. (2010) Database 2010, bap024. doi:10.1093/database/bap024

(20) Pérez-Jiménez, J., Neveu, V., Vos, F., \& Scalbert, A. (2010) Eur. J. Clin. Nutr. 64, S112-S120. doi:10.1038/ejen.2010.221

(21) Gallo, M., Vinci, G., Graziani, G., De Simone, C., \& Ferranti, P. (2013) Food Res. Int. 54, 406-415. doi:10.1016/j. foodres.2013.07.011

(22) Jobstl, E., O'Connell, J., Fairclough, J.P.A., \& Williamson, M.P. (2004) Biomacromolecules 5, 942-949. doi:10.1021/bm0345110

(23) Cardona, F., Andrés-Lacueva, C., Tulipani, S., Tinahones, F.J., \& Queipo-Ortuño, M.I. (2013) J. Nutr. Biochem. 24, 1415-1422. doi:10.1016/j.jnutbio.2013.05.001

(24) Liu, Z., Bruins, M.E., Ni, L., \& Vincken, J.-P. (2018) J. Agric. Food Chem. 66, 8469-8477. doi:10.1021/acs.jafc.8b02233

(25) Ibero-Baraibar, I., Suarez, M., Arola-Arnal, A., Zulet, M.A., \& Martinez, J.A. (2015) Food Nutr. Res. 60, 30449. doi:10.3402/ fnr.v60.30449

(26) Rothwell, J.A., Urpi-Sarda, M., Boto-Ordonez, M., Knox, C., Llorach, R., Eisner, R., Cruz, J., Neveu, V., Wishart, D., Manach, C., Andres-Lacueva, C., \& Scalbert, A. (2012) Database 2012, bas031. doi:10.1093/database/bas031

(27) Gonthier, M.P., Remesy, C., Scalbert, A., Cheynier, V., Souquet, J.M., Poutanen, K., \& Aura, A.M. (2006) Biomed. Pharmacother. 60, 536-540. doi:10.1016/j.biopha.2006.07.084

(28) Zhang, H., Yu, D., Sun, J., Guo, H., Ding, Q., Liu, R., \& Ren, F. (2014) J. Mol. Struct. 1058, 228-233. doi:10.1016/j. molstruc.2013.11.009 